\title{
Longitudinal connectivity loss in a riverine network: accounting for the likelihood of upstream and downstream movement across dams
}

\author{
Gonzalo Rincón, Joaquín Solana-Gutiérrez, Carlos Alonso, Santiago Saura \\ Diego García de Jalón
}

\begin{abstract}
Disruption of longitudinal connectivity is a major concern in most of the world's rivers. Approaches based on graph theory have proven to be a suitable tool for analysing functional connectivity. However, previous applications of graph-based connectivity methods to river systems have been oversimplified in that they have treated potential barriers as binary features and rivers as symmetric networks. We here apply a network analytical approach in which (a) upstream and downstream connectivity are considered so that fish passability values across dams are asymmetrical, and (b) it is possible to consider a continuous range of passability values for every dam. We build on previous and widely used connectivity metrics (Probability of Connectivity, PC), which here are generalised and adapted toward that end. We compare the results of our approach with those that would be obtained under the more simplified assumptions of symmetric movement and of barriers as binary features. We want to prove if there are substantial differences between considering or not the asymmetry in river networks. The application of symmetrical and asymmetrical PC highlights major differences between the upstream connectivity versus the downstream connectivity. We provide our methods in a free software package so that they can be used in any other application to riverscapes. We expect to provide a better graph-based approach for the prioritisation of the removal or permeabilization of artificial obstacles as well as for the preservation of target river segments for connectivity conservation and restoration.
\end{abstract}

Keywords Longitudinal connectivity · Fish passability · Graph theory · Directional networks · Asymmetric dispersal $\cdot$ Riverscapes

\section{Introduction}

Connectivity is the extent to which a species or populations can move among landscape elements in a mosaic of habitat types (Hilty et al. 2012). This concept is an essential property for the functioning of ecosystems (Kondolf et al. 2006). It is especially important for sustaining ecological flows (i.e. matter and energy) and the movement of genes, individuals or populations (Nicola et al. 1996; Calabrese and Fagan 2004). Given the decisive role of connectivity for the long-term persistence of biodiversity, it is widely acknowledged that it should be considered in decisionmaking and in the management planning processes in landscapes and riverscapes (Erös et al. 2011).

Rivers are considered as the epitome of connectivity (Wiens 2002). Therefore, special attention must be paid to the longitudinal dimension of connectivity (Ward 1989; Tockner et al. 1998; Lucas et al. 2001). Human activities, such as flow regulation produced by dams, disrupt the upstream-downstream linkages (Ward 1989). More specifically, dams reduce connectivity and, by doing so, they hinder or impede fish migration up or downstream and increasing demographic isolation of the biological populations (Schick and Lindley 2007).

The loss of longitudinal connectivity in rivers as a result of dam development is a major worldwide problem (Gough et al. 2012). In the European Union, the EU Water Framework Directive (WFD, 2000/60/CE) considers river continuity as one of the aims for achieving good ecological status of the water bodies. River continuity is 
defined as having "no disruption of migration of aquatic organisms and sediment transport". Restoration of the longitudinal connectivity of rivers will have positive impacts on freshwater fish populations, especially on those obligated to migrate to complete their life cycle (Segurado et al. 2014). However, limited budget allocations often restrict the extent of connectivity restoration programmes. Therefore, it is necessary prioritise connectivity restoration actions in order to maximise their benefits for the riverine network functioning (Rivers-Moore et al. 2016). The strategy often depends on assessment of the contribution of every barrier to the overall loss of connectivity, as well as a subsequent ranking of the relevance of the removal of every barrier to the restoration of connectivity.

The graph-based methodology has proven to be a useful tool for quantifying the overall habitat connectivity of freshwater systems (Schick and Lindley 2007; Erös et al. 2011, 2012; Carranza et al. 2012), being a widely used technique in terrestrial landscapes (Minor and Urban 2007, 2008; Bodin and; Saura 2010; Saura and Rubio 2010). Ecological systems can be represented as graphs or networks that contain nodes depicting individual elements and links representing relationships between the nodes (Bodin 2009; Erös et al. 2012). Based in this concept, software tools like Conefor (Saura and Torné 2009) have been developed. River segments and barriers can be represented in the graph, and their individual importance in the overall connectivity of the river system can be assessed. This approach yields a value of the overall connectivity of a given river network, and the partial contribution of every single obstacle to the loss of overall connectivity.

Previous applications of graph theory quantifying the longitudinal connectivity loss in riverine systems and ranking barriers have relied in two main assumptions: (1) barrier passability values are binary (or impassable or totally passable), and (2) non-directionality movement (see Erös et al. 2011; Segurado et al. 2013, 2014). These assumptions about the symmetric passability of barriers do not agree with the idea of the importance of asymmetry in river systems. Asymmetry of movement in dendritic ecological networks (Grant et al. 2007) is an extremely important concept in the analyses of metapopulations in rivers and possible biases in the upstream-downstream movements (Grant 2011). Therefore, the consideration of directionality in riverine networks is needed in order to build up more ecologically realistic and functional models (Padgham and Webb 2010). We propose to take the idea of Segurado et al. (2013) and improve it by considering the asymmetry of the obstacles passability. We will test the efficiency of this improvement by comparing both approaches: one assuming symmetric passability and a more realistic one taking into account the asymmetry.
To do this, we applied a graph-based approach to account for asymmetrical passability in river connectivity assessments obtaining different graph resolutions to prioritise barriers. We used a directional version of the Probability of connectivity (PC) metric (Saura and Pascual-Hortal 2007) differing between upstream and downstream passability for barriers (González Fernández et al. 2010). We quantified the loss of overall connectivity in a real river system due to obstacles through the comparison of two landscape connectivity indices: Integral Index of Connectivity (IIC) (Pascual-Hortal and Saura 2006), which relies in binary barriers, and the Probability of Connectivity (PC), which allows for a continuous range of passability values to be assigned to each barrier. By comparing the results of both indices, we assessed the effect of assuming symmetrical passabilities and binary barriers in the overall account of connectivity and in related barrier prioritization.

To test the error caused by not taking into consideration the asymmetry, we estimated the overall connectivity of two scenarios in a case study: (1) assuming symmetry in the passability of every obstacle; and (2) considering the asymmetry of the barriers that are really, which is in line with reality. Both situations could not be very different, but both are a real case study and then representative of the problem. If the results are different when considering or not asymmetry, a description of these differences allow explain the error committed if we assume that all obstacles are symmetrical in a real case. Higher values of overall connectivity are expected to occur when obstacles have different passability values in both directions. By doing so, we expect to provide a better graphbased approach, and to quantify the difference they make compared to previous graph-based assessments in rivers, for the prioritisation of the removal or permeabilization of artificial obstacles, as well as for the preservation of target river segments for connectivity conservation and restoration.

Mediterranean river systems exhibit large flow variability and frequently are naturally disconnected during part of the year. This hydrological variability produces unequal changes in upstream and downstream fish passabilities. For this reason determining connectivity losses in Iberian rivers is an issue (Branco et al. 2012). This study provides the approach of considering the movement in both directions, upstream and downstream, to implement a methodology that better fits the natural river conditions. In this regard, it is advisable to apply the idea of asymmetry for a better representation of the impact on connectivity and the movement of fish species due to the presence of artificial obstacles. 


\section{Materials and methods}

\section{Study area}

The study area is located in the north-west part of the Iberian Peninsula and is comprised of the catchments of the Cega and Pirón Rivers within the Duero River basin (Fig. 1a). Both are small Mediterranean rivers with a pluvio-nival hydrological regime, presenting severe droughts in the summer. The Cega River has a total length of $149 \mathrm{~km}$, drains an area of $2579 \mathrm{~km}^{2}$ and flows mainly from south to north presenting an average total annual discharge of $232.1 \mathrm{hm}^{3}$ (CHD 2009). Its main tributary is the Pirón River with a length of $98 \mathrm{~km}$, a basin area of $1024 \mathrm{~km}^{2}$ and an average annual discharge of $74 \mathrm{hm}^{3}$. The flow regime in the Cega River is not regulated. The Pirón River is regulated and affected by a major loss of longitudinal connectivity due to the presence of the Torrecaballeros Dam (height $26 \mathrm{~m}$; capacity $0.324 \mathrm{hm}^{3}$ ) in its headwaters (see Fig. 1a, b).

\section{Fish communities}

Fish communities in the catchments of the Cega and Pirón Rivers are dominated by brown trout, Salmo trutta (density 12.2 ind. ha $^{-1}, 44 \%$ out of the density of the fish community). Three rheophyllic cyprinids are the sub-dominant species: bermejuela, Achondrostoma arcasii (8.1 ind. ha ${ }^{-1}$, 30\%); Northern Iberian chub, Squalius carolitertii (3.6 ind. $\left.\mathrm{ha}^{-1}, 13 \%\right)$; and Iberian gudgeon, Gobio lozanoi (3.3 ind. $\left.\mathrm{ha}^{-1}, 12 \%\right)$. The Iberian barbel, Luciobarbus bocagei $(0.13$ ind. $\left.\mathrm{ha}^{-1}, 0.5 \%\right)$, spined loach, Cobitis calderoni $(0.05$ ind. $\left.\mathrm{ha}^{-1}, 0.2 \%\right)$, and tench, Tinca tinca $\left(0.01\right.$ ind. $\left.\mathrm{ha}^{-1}, 0.04 \%\right)$ are the accompanying species (Junta de Castilla y León 1997).

These species are common to both rivers, except for the Iberian barbel, which only appears in the Cega River, and the common carp (Cyprinus carpio), which is found only in the Pirón. The distributional pattern along the longitudinal gradient (upstream to downstream) is very similar in both rivers: trout—chub/nase—bermejuela—spined

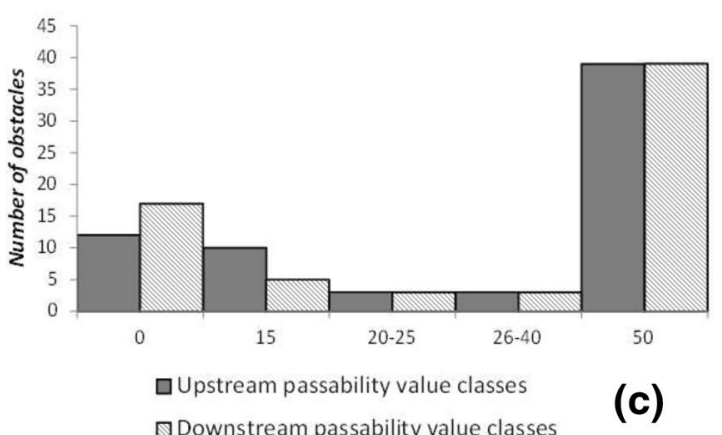

(a)

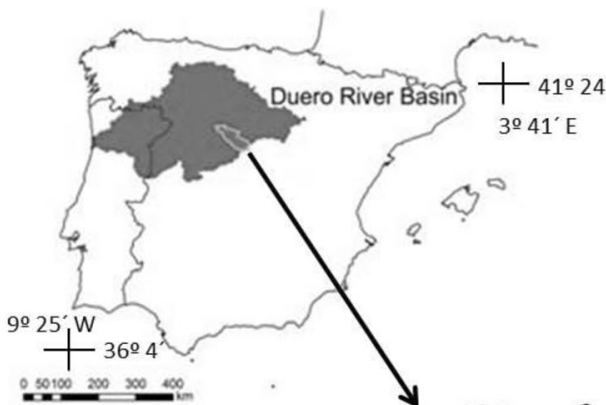

$\square$ Downstream passability value classes

(c)

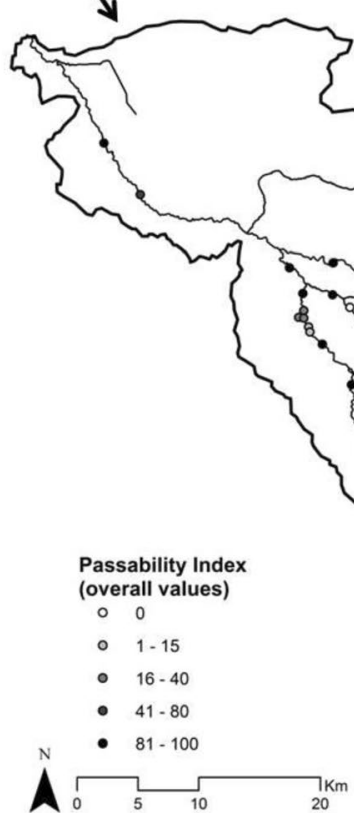

Fig. 1 a Map of the Duero River basin located on the Iberian Peninsula. b The Cega and Pirón River basin. Black points in this figure represent artificial barriers in the fluvial network. $\mathbf{c}$ Number of obstacles in the river network based on their upstream and downstream passability values 
loach — barbel/gudgeon in the case of the Cega River, and trout—bermejuela/chub—nase—spined loach/gudgeoncarp for the Pirón River.

We studied connectivity by focusing on the requirements of the fish communities of the Cega and Pirón Rivers. The overall connectivity depends on the passability values of each obstacle and the ability of fish species to cross them both upstream and downstream.

\section{Inventory of barriers}

To determine the overall connectivity of the Cega and Pirón river network, we developed an inventory of all artificial alterations to the longitudinal river continuity based on aerial photographs of the rivers. A total of 22 obstacles were detected, including large dams, weirs and other barriers, in the Cega and 20 were found in the Pirón (González Fernández et al. 2010; CHD 2009). Tributaries of both rivers were also affected by obstacles: 11 additional obstacles were found in the Cega catchment and 14 in the Pirón subcatchment, resulting in a total set of 67 obstacles for the entire river network (see Fig. 1b).

\section{Fish passability values}

The concept of barrier passability is difficult to define (though a rough definition could be a barrier's capability of being passed). However, there are many methods for estimating passability (Bourne et al. 2011). The passability of an obstacle must be analysed according to the attributes of each barrier and the requirements and possibilities of passage of each fish species in both directions (Cote et al. 2009; Bourne et al. 2011; Januchowski-Hartley et al. 2013). However, there is some uncertainty surrounding this concept due to the difficulty in estimating the mean passability of a dam for a fish species. Mean passability is linked to fish physiology, which may vary depending not only on the species but on the size and other individual traits. Additionally, the attributes of the barriers change depending on the flow conditions (Bjornn and Peery 1992), affecting the actual fish passability.

To determine the passability of the Cega and Pirón river network barriers, we have relied on the study "Longitudinal connectivity diagnosis in the Duero River Basin" (González Fernández et al. 2010, report commissioned by the Duero River Basin Authority, available only in Spanish) where a passability index is developed. This index ranges from 0 to 100 and is the sum of the upstream and downstream passability for each obstacle. Upstream and downstream passability values are estimated from 0 to 50 , being 0 the maximum passability value and 50 the minimum value in each direction of movement. This index mainly depend on the physical parameters of the obstacle, therefore the upstream passability depends on the dam wall height, dam wall upper sill, dam wall slope, downstream ponds, fish passage structures and hydraulic features (i.e. flow, upstream and downstream depth, water velocity, water temperature, water jet streams). Conversely, downstream passability is mainly related to the probability of fish straying in big dams and the features of spillways, water inlets, conduction pipes and water connections, among other factors. In parallel, the fish species that live in the river were clustered into five groups according to their swimming performance and migratory life tactics. Group 1 are fish species with high swimming and jump ability, i.e. salmonids like Salmo trutta. Group 2 are fish species of cyprinids with high swimming and low jump ability, i.e. migratory cyprinids like Luciobarbus bocagei. Group 3 are fish species of cyprinids with moderate movement and low jump capacity, i.e. small migratory cyprinids like Gobio lozanoi. Group 4 are slow water fish with no ability to jump like Tinca tinca. Finally, Group 5 are benthonic fish like Cobitis calderoni. Once these values are collected, a matrix which contains the connectivity information for each obstacle in two directions and depending on the fish species that lives in the river segment is developed. To handle this matrix, a value of 10 has been assigned to an obstacle when it is impassable for a given group of fish species, a value of 5 when it is variable (depending on the flow) and a value of 0 when the obstacle is totally passable. So, the passability index is defined as the sum of the values of upstream and downstream passability for each of the fish groups considered according to the following formula: Passability Index $(\mathrm{PI})=$ Passability Upstream + Passability Downstream $=$ PUp. (Gro up 1 + Group2 + Group3 + Group4 + Group5) + PDown. (Group1 + Group2 + Group3 + Group4+ Group5). Example: for a total value of $65, \mathrm{PI}=$ Pup. + Pdown. $=$ Pup. $(5+5+10+10+10)+$ Pdown. $\quad(5+5+5+5+5)=$ Pup. (40) + Pdown. $(25)=65$, this means that this particular obstacle is practically impassable in the ascent (Passability Upstream $=40$ ) and moderately passable in the descent (Passability Downstream $=25$ ).

The essence of this index is based on the higher the probability to cross, the lower the index value (Fig. 1c). We consider that this definition is not intuitive so we have define a passability probability value, named Connectivity Index (hereafter CI) which reflects the chance for a fish to pass through the dam in both senses: upstream and downstream. This CI is a positive number, smaller than one, and is inversely proportional to the passability index which González Fernández et al. (2010) defined (see Table 1). After calculating the upstream and downstream passability values for each barrier, a graph was developed as described in next section. 
Table 1 Data on 20 connectors, including (1) the fluvial network to which they belong, (2) the connector number, (3) the values of the index defined by González Fernández et al. 2010 including overall PI value and the separated PI value in both directions of each connector, and (4) the probability of passability (CI) in both directions of each connector

\begin{tabular}{|c|c|c|c|c|c|c|}
\hline \multirow[t]{2}{*}{ River basin } & \multirow[t]{2}{*}{$\begin{array}{l}\text { Connector } \\
\text { number }\end{array}$} & \multicolumn{3}{|c|}{$\begin{array}{l}\text { Passability index (PI) defined by González } \\
\text { Fernández et al. } 2010\end{array}$} & \multicolumn{2}{|c|}{ Connectivity index (CI) } \\
\hline & & Total & Upstream & Downstream & $\begin{array}{l}\text { Upstream } \\
1-(\mathrm{PI} / 50)\end{array}$ & $\begin{array}{l}\text { Down- } \\
\text { stream } \\
1-(\mathrm{PI} / 50)\end{array}$ \\
\hline \multirow[t]{10}{*}{ Cega } & 2 & 0 & 0 & 0 & 1 & 1 \\
\hline & 3 & 0 & 0 & 0 & 1 & 1 \\
\hline & 4 & 100 & 50 & 50 & 0 & 0 \\
\hline & 5 & 70 & 40 & 30 & 0.2 & 0.4 \\
\hline & 22 & 100 & 50 & 50 & 0 & 0 \\
\hline & 28 & 0 & 0 & 0 & 1 & 1 \\
\hline & 29 & 100 & 50 & 50 & 0 & 0 \\
\hline & 48 & 100 & 50 & 50 & 0 & 0 \\
\hline & 49 & 80 & 40 & 40 & 0.2 & 0.2 \\
\hline & 53 & 100 & 50 & 50 & 0 & 0 \\
\hline \multirow[t]{10}{*}{ Pirón } & 55 & 100 & 50 & 50 & 0 & 0 \\
\hline & 59 & 30 & 15 & 15 & 0.7 & 0.7 \\
\hline & 60 & 40 & 20 & 20 & 0.6 & 0.6 \\
\hline & 66 & 30 & 15 & 15 & 0.7 & 0.7 \\
\hline & 67 & 30 & 15 & 15 & 0.7 & 0.7 \\
\hline & 68 & 30 & 15 & 15 & 0.7 & 0.7 \\
\hline & 78 & 90 & 50 & 40 & 0 & 0.2 \\
\hline & 79 & 35 & 15 & 20 & 0.7 & 0.6 \\
\hline & 100 & 30 & 15 & 15 & 0.7 & 0.7 \\
\hline & 102 & 65 & 40 & 25 & 0.2 & 0.5 \\
\hline
\end{tabular}

\section{Estimating the connectivity loss by dams}

In order to quantify the loss of connectivity in these rivers due to the presence of potential barriers, we used an approach based on graph theory (Erös et al. 2011, 2012; Segurado et al. 2013, 2014). We represented the Cega and Pirón river network as a graph (Fig. 2). Then, we modelled the effects of obstacles on the longitudinal connectivity of these rivers. For the hydrological modelling of freshwater bodies, it is useful to consider the stream segments as nodes. In this methodological approach, each river segment (node) has some amount of associated habitat, which is represented here as a combination of the length and mean width of the segment. Then, these segments are joined by links or connectors with different strengths (passabilities) that can be headwaters, confluences (river junctions), river mouth and transversal obstacles (dams and weirs). These elements are considered to be connectors because they determine the connection of each river segment to the previous and subsequent ones.

In addition, each link between river segments has a probability value (CI) that reflects the chance that a fish passes through the connector. In the graph (Fig. 2), the junction of two river segments will have full probability of movement; the CI will be 1 . However, if the segment is limited by an insurmountable barrier, then the CI value will be 0 , which means that there will be no possibility to cross and therefore the segments will be disconnected (Table 1).

Once the graph is built and each node and link are characterised, the relevance of each particular node and link for the overall connectivity of the basin is calculated. To measure the overall connectivity of the whole river system, we used the Probability of Connectivity index (PC) (Saura and Pascual-Hortal 2007), which allows for modulating the passability of each particular obstacle in a continuous range from 0 to 1 . The results of the PC were also compared to those provided by the Integral Index of Connectivity (IIC) (Pascual-Hortal and Saura 2006), which has been used in previous studies related to river networks (Segurado et al. 2013; Erös et al. 2011) and only allows for including either full barriers or fully permeable junctions along the river network. The IIC is a connection index based on a binary system by which two habitat patches are either connected or disconnected without intermediate modulation of the strength of the connection between both patches and viability of dispersion (Fig. 3). The PC and IIC increase with higher connectivity and range from 0 to 1 . Both are also topo-ecological indices, i.e. they account for the attributes of the habitat patches along with the topological relationships between those patches within the network (Saura 


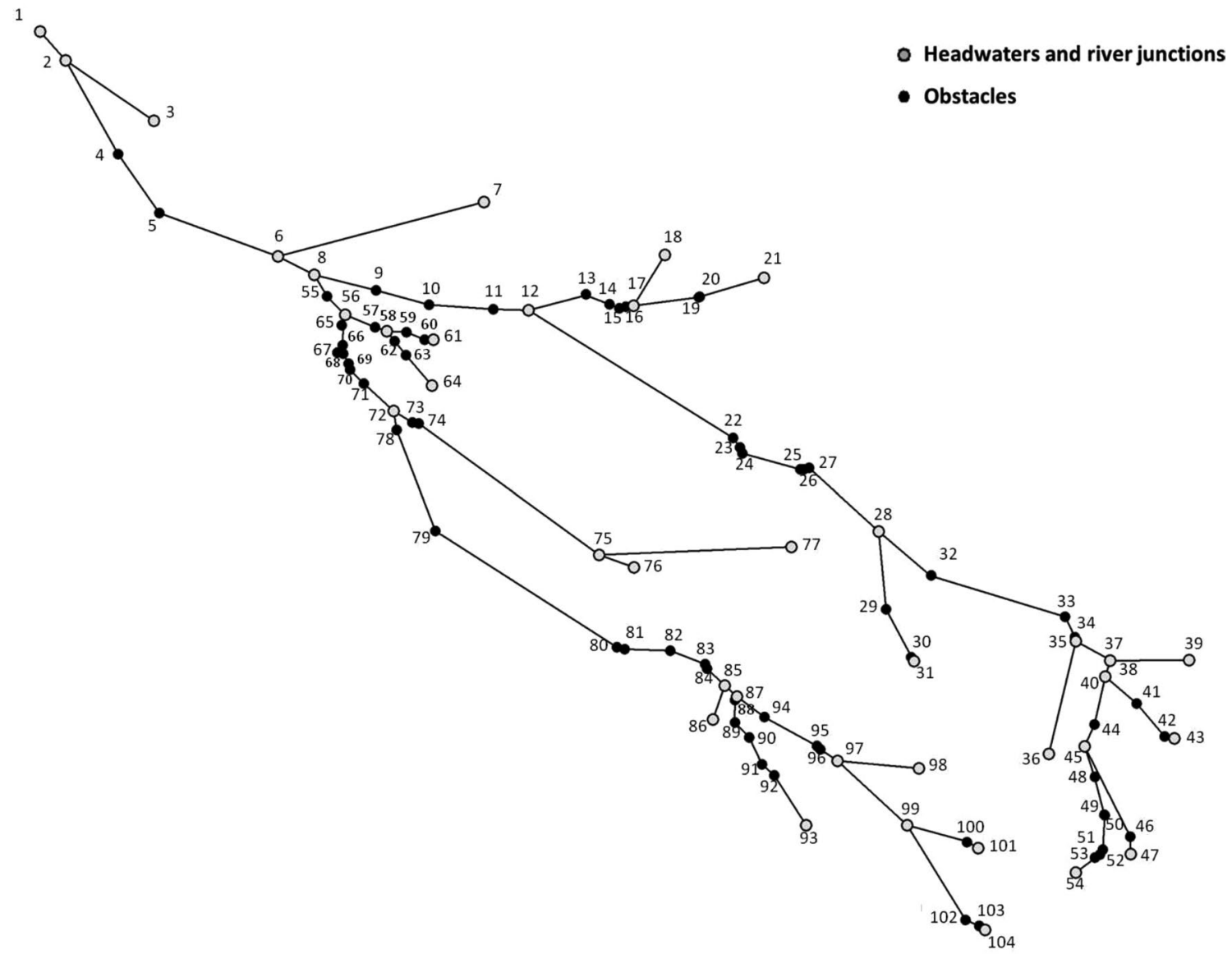

Fig. 2 Graph representation of the Cega and Pirón river network. Grey circles represent headwaters and joints between two watercourses, whereas black circles represent barriers. Each river segment is delimited by two numbered connectors

and Rubio 2010). The two connectivity indices (both the PC and the IIC) were calculated using the software package Conefor (Saura and Torné 2009; available at http:// www.conefor.org). Furthermore, the PC for asymmetric graphs was computed using a purposefully developed version of the Conefor command line (available under request to authors).

\section{Application of habitat availability indices to prioritise connectivity conservation and/or improvement}

The contribution of each node or river segment to the overall connectivity was assessed by calculating the percent variation in the values of the indices after removal of that particular segment from the river network (dIIC and dPC, where $d$ means the percentage of the variation). The contribution of landscape elements (in this case, river segments) to the overall connectivity can be divided into the sum of three sub-indices: intra, flux and connector (Saura and Rubio 2010).

The intra fraction represents the intrapatch connectivity (habitat resources that can be reached within a given segment, without moving to other segments). This fraction is independent of how a node is connected with the others. The flux fraction reflects how well connected a segment is to the rest of the habitat segments in the river network. The connector fraction represents how important a given segment is for maintaining the rest of the habitat segments connected to each other. For this reason, this fraction is particularly relevant to this study due to the special characteristic of river systems: one single path of movement (the river stream) without other possible alternative paths making these ecosystems exceptionally vulnerable to fragmentation (Erös and Grant 2015). This feature of river systems is what makes the connector fraction essential, acting as a bridge patch or "stepping stone".

On the other hand, evaluating the contribution of each link allows us to determine the effects on the connectivity of the removal of an obstacle (dam or weir). This feature was assessed by recalculating the connectivity indices, considering that a given link is fully passable (no restrictions on movement between two particular segments). In the probabilistic model of the PC, this translates as the connection between segments having 


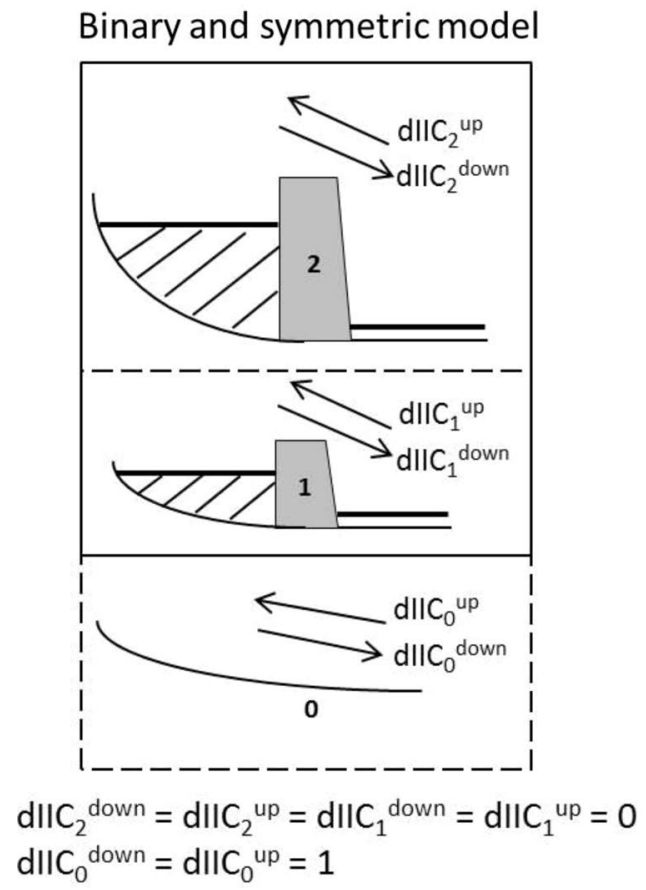

Fig. 3 Schematic comparison between the results of applying the IIC and PC indices to different river scenarios. A simple visual representation of the three possible connectivity situations in the rivers is shown: a river in natural conditions without obstacles $(0)$, small weirs that can be assumed to be a hindrance to connectivity depending on

a probability equal to 1 of conducting movement, i.e. the probability of circulation between two pairs of segments will be 1 rather than the resistance value it had before. In a riverine network, we only consider the pairs of segments with a direct connection between them. Calculations were performed using the "link improvement" functionality of the Conefor software package (Saura and Torné 2012).

\section{Determining the reliability of considering the river as a symmetric model}

In order to test the effectiveness of using an asymmetrical version of $\mathrm{PC}$ versus the symmetrical one used in previous studies, we compared both indices through the generation of two different scenarios with different movement characteristics: (1) a scenario where downstream passability is only considered, and then all barriers are impassible for the upstream movement and totally passable for the downstream movement and (2) a scenario where upstream passability is only considered, with inverse conditions to the previous scenario.

\section{Continuous and asymmetric model}

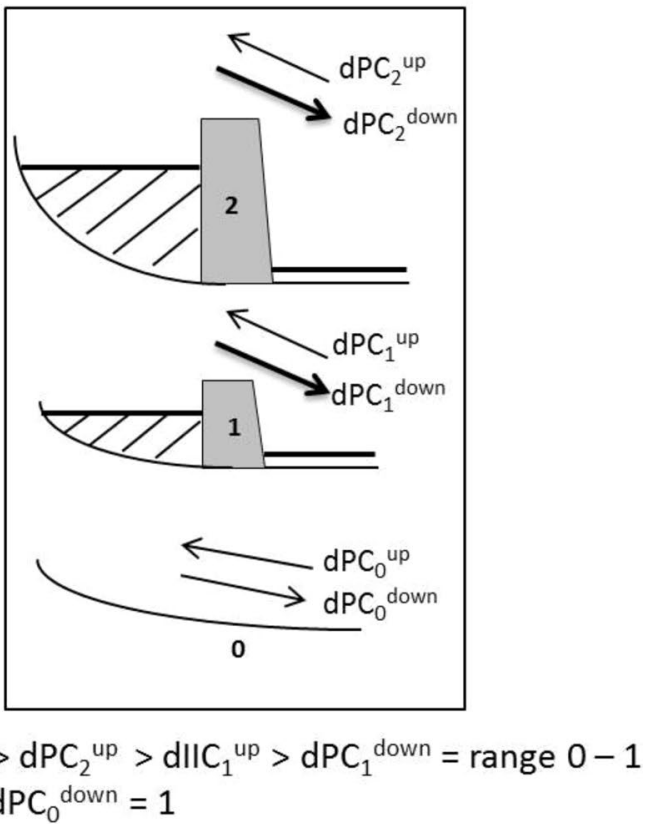

some different attributes (fish species, river flow and physical characteristics of the obstacle) (1), and big dams that generate disruption to the river connectivity (2). The left side shows the results of the application of dIIC whereas the dPC results are shown on the right

\section{Results}

\section{Converting the fluvial system into a graph}

In the absence of obstacles, the graph depiction would be comprised of the river segments linked by the junctions of the main river and its tributaries. By adding the dams and weirs, the number of segments in the graph rises from 38 to 104 (Fig. 2). According to the CI values, the number of impassable obstacles in both directions for the Cega River and its tributaries reaches 21, while for the Pirón, it is 17. The remaining obstacles in the Cega River are considered easy to overcome because, except for three cases, they possess CI values between 1 and 0.7. In the Pirón River nine obstacles with $\mathrm{CI}$ values between 0.7 and 0.6 are found.

\section{Application of connectivity indices to the fluvial basin}

Both the IIC and the PC indices have determined which of the river segments are the most sensitive to the loss of connectivity and thus, are more valuable for removing or permeabilising dams (Fig. 4). The values of the connector fraction and the position on the ranking of influence for the 

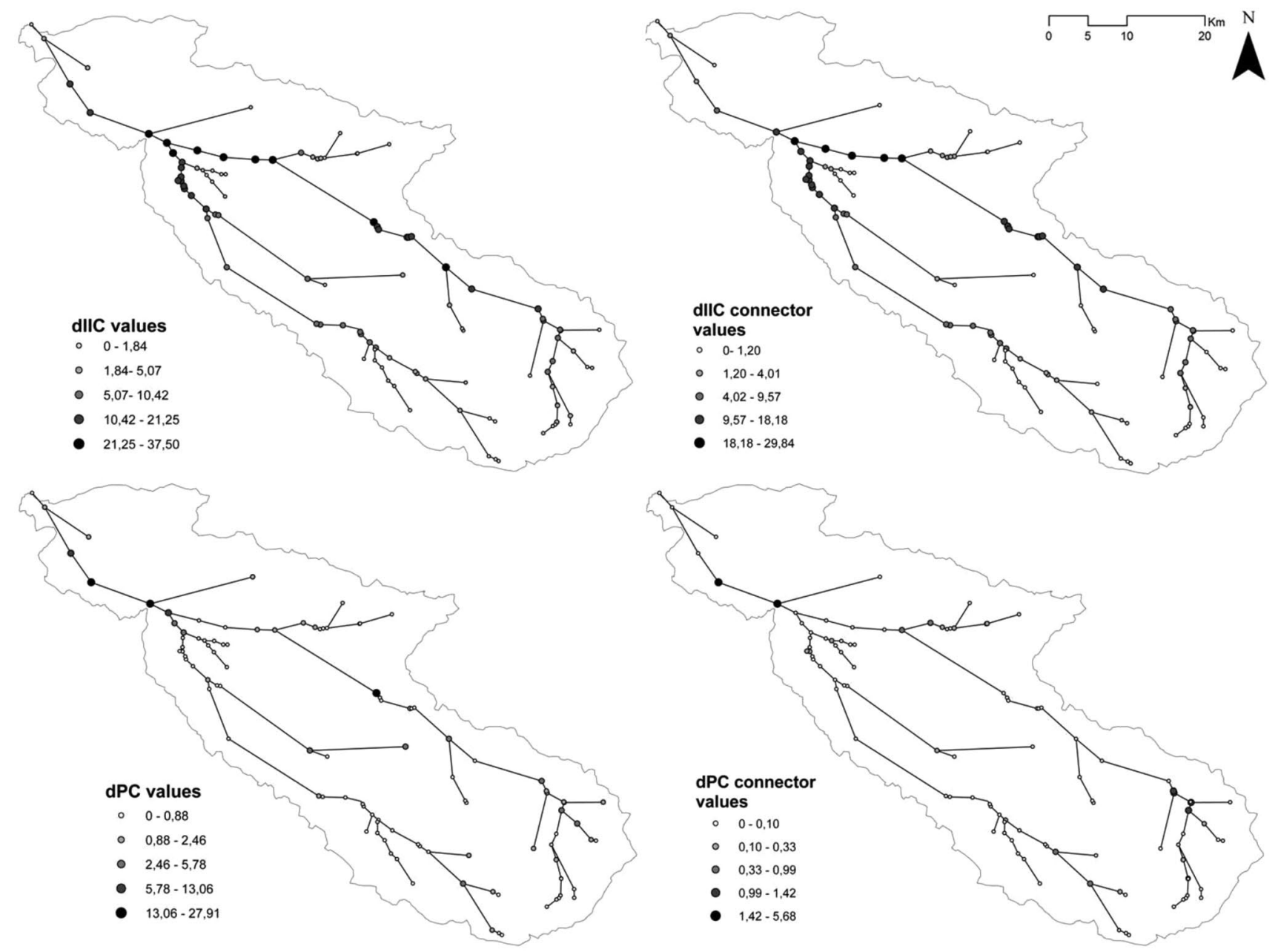

Fig. 4 Graph-based representation of the Cega and Pirón Rivers using the dIIC and dPC indices and their corresponding connection fraction. The darkest circles represent elements with high connectivity values and thus are targets for conservation

overall connectivity differ when one or the other index is applied. These differences are a result of both the positions of the nodes in the network and of the characteristics of the barriers or links among them. The dIIC and dPC ranking results were substantially different for the same segment: only $45 \%$ of the barriers are coincident in both approaches. The lowest dPC values were found in segments located in the upper reaches of small streams or near an insurmountable obstacle that prevents the movement of fish species. On the other hand, the highest values were found in the lower reach, where the Pirón meets the Cega, in the Cega main watercourse and in the segments with fewer obstacles. The contribution of each river segment, measured by the IIC and PC, is shown in Fig. 3. In the case of the dIIC, $60 \%$ of the 20 most important connectors corresponded to river segments that were limited by insurmountable barriers, whereas in the case of the dPC, only a $35 \%$ of the segments are limited by barriers that are totally insurmountable in both directions. This means that, in this case, considering the IIC index instead of the PC, the loss of connectivity has been overestimated.

With respect to the results of the connector fraction, we can define which river segments need to be prioritised, i.e. those where it is critical to keep high levels of connectivity throughout the river. In this case, when the dIICconnector was applied, 55\% of the segments were limited by insurmountable barriers, while the percentage was reduced to $5 \%$ when using the dPCconnector. In the case of the dPCconnector, the connectors with high values are located at the confluence of the waterways, as shown in Fig. 4; for that reason, they are characterised as being especially important in the conservation of these river networks.

The application of the link improvement procedure generated a ranking of the barriers that hinder fluvial continuity. This ranking determines that connector 55 is the major disruptor in connectivity, followed by connectors 22,5 , 4, 37 and 9. This is a consequence of the strategic topological position of these barriers in the network, mostly in 
the downstream sections or in the junctions among important segments, generating a disconnection with the upper reaches of the river.

\section{Comparison between the symmetric and asymmetric PC approach}

Results from the application of the symmetric and the asymmetric versions of PC suggest important differences between both versions, highlighting that a symmetric passability should not be assumed in connectivity studies for river systems. While the differences in the ranking are limited so that the first nine segments are equal in both cases, the results of the connector fraction differ between both symmetric and asymmetric approaches (Table 2). The difference between the dPC values when considering symmetric and asymmetric passability is around 9\%, evaluated through the sum of the differences. In the connector fraction, this sum rises to $24.89 \%$. In this particular case, the majority of the obstacles have a symmetric passability. The sum of the differences between the upstream CI and

Table 2 Comparison of dPC and dPCconnector values in the study area using different versions of the PC index (symmetric versus asymmetric) for the 20 most important connectors

\begin{tabular}{|c|c|c|c|}
\hline \multicolumn{2}{|c|}{ dPC } & \multicolumn{2}{|c|}{ dPCconnector } \\
\hline symmetric & asymmetric & symmetric & asymmetric \\
\hline 6 & $\rightarrow 6$ & 6 & $\rightarrow 6$ \\
\hline $22-$ & $\rightarrow 22$ & 5 & $\rightarrow 5$ \\
\hline 5 & $\rightarrow 5$ & 40 & 38 \\
\hline $8-$ & $\rightarrow 8$ & 38 & 40 \\
\hline 4 & $\rightarrow \quad 4$ & 35 & 35 \\
\hline 75 & $\rightarrow 75$ & 34 & 34 \\
\hline 28 & $\rightarrow 28$ & 41 & 12 \\
\hline 77 & $\rightarrow 77$ & 1 & 99 \\
\hline 33 & $\rightarrow 33$ & 9 & 97 \\
\hline 40 & 55 & 13 & 13 \\
\hline 5 & 56 & 48 & 41 \\
\hline 56 & & 42 & 75 \\
\hline 99 & 34 & 75 & 20 \\
\hline 41 & 13 & 20 & 17 \\
\hline 38 & & 17 & \\
\hline 48 & & $\begin{array}{l}14 \\
68\end{array}$ & $\begin{array}{l}48 \\
68\end{array}$ \\
\hline 13 & 11 & 67. & 50 \\
\hline 80 & 36 & 58 & $\rightarrow 67$ \\
\hline $12 /$ & 7 & 19 & $\rightarrow 58$ \\
\hline
\end{tabular}

Each column contains the number of the connector, ordered according to its importance in the overall connectivity. Black arrows represent correspondence between the connectors in both models downstream CI values is around $6.7 \%$ of the mean values of both CIs.

The differences between the asymmetric and the symmetric perspectives are emphasised in the case of upstream connectivity (20 major differences versus 14 in the case of downstream connectivity) (Fig. 5). Normally, the symmetric index overestimates the importance of the connector (yellow circles), except for five connectors of the middle reach of the river (the orange circles 22, 28, 33, 75 and 77), in which the dPCconnector for the asymmetric network exceeds the value of the symmetric case.

A pair of graphics has been developed to represent differences in the use of the $\mathrm{APC}$ index from upstream and downstream passability (Fig. 6). Higher overweights in the symmetric indicator are found in the downstream connectors, specifically in numbers 6, 5, 4, 99 and 102 (yellow). In connector 22 , the asymmetric index has a higher value than does the symmetric (orange circle), indicating a higher level of importance of this element. Regarding upstream connectivity, the pattern is similar: an overweight of the symmetric indicator for connectors 6, 5, 4, 48, 49, 99, 100 and 102 , but with a lower bias (i.e. smaller absolute value). The dPC value of connector 22 is smaller in the asymmetric analysis. However, this difference is smaller compared in this upstream direction than in the downstream one (Fig. 6a, b).

The graph model was evaluated to determine the importance of the connectors according to their dPC upstream value. We observed that the most important barriers/links are connectors 5, 6 and 8, where an asymmetry exists in the probability of passability. On the other hand, connector 22 has a high value but its probability of passability upstream and downstream is symmetric. It is noticeable that among the main connectors, both barriers (i.e. 22 with a value of 20.6 or 5 with 16.5) and river junctions (i.e. 6 with a value of $27.3 ; 8$ with $13.2 ; 75$ with 6.2 or 28 with 5.2 ) are included.

It seems that the number of overestimations is lower in the asymmetric model (32 yellow circles against 72 in orange). It is also interesting that in the lower part of the basin, overestimation of the importance calculated by the symmetrical method is more common, while in the upper reaches underestimation of the node importance is more frequent (i.e. in the figure, orange nodes are more abundant) (Fig. 6c, d).

\section{Discussion}

This study supports the view that graph-based methodologies are effective tools for identifying the obstacles that make the greatest contributions to the overall loss of longitudinal connectivity in rivers. Moreover, these methods 


\section{Major differences dPC Upstream}

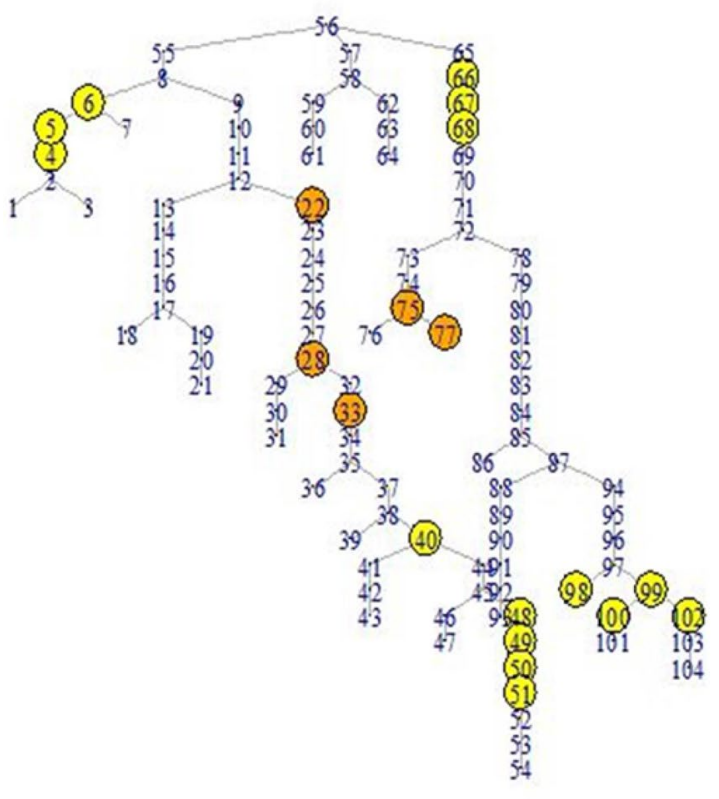

Symmetric_UP > Asymmetric_UP (yellow)

\section{Major differences dPC Downstream}

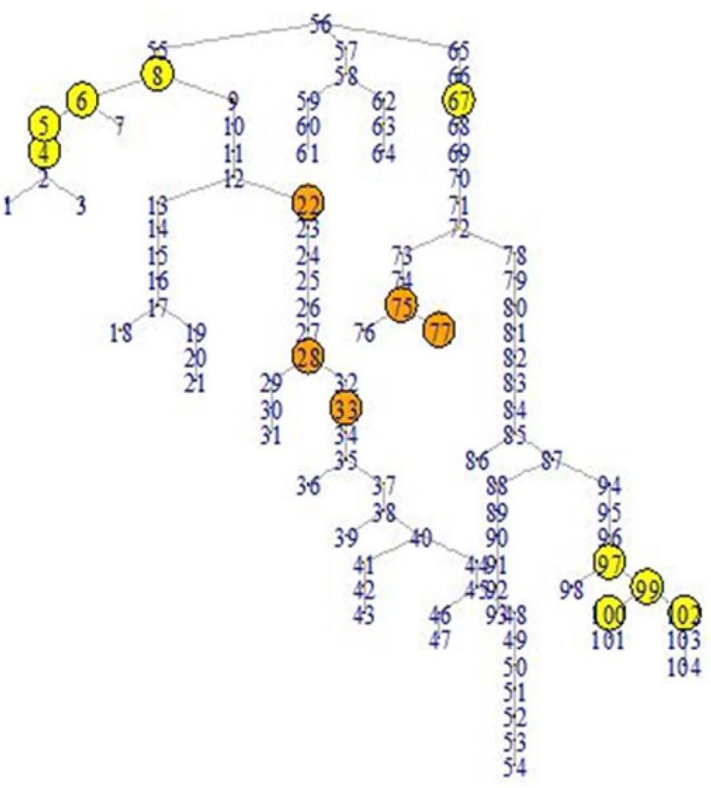

Symmetric_DOWN > Asymmetric_DOWN (yellow)

Yellow filled circles imply an overestimation of the symmetric version versus the asymmetric one, while orange filled circles represent an underestimation

instead of the area, as the proxy of the habitat attribute that is assigned to every node in the calculation of the PC metric (Cote et al. 2009).

Connectivity is likely non-additive (O’Hanley and Tomberlin 2005, O'Hanley 2011), that is, the impact of removing many clusters of dams is not necessarily equivalent to the sum of the impact of removing individual obstacles separately. However, the approach and tools used in this research are equally applicable for evaluating the cumulative effect of removing several obstacles at a time.

\section{Considering a continuous range of passability values rather than treating all obstacles as full or no barriers}

Saura and Pascual-Hortal (2007) suggested the application of IIC and PC among the existing indices used to calculate ecological connectivity. Between those two indices, they recommend the application of the PC because the IIC can generate an oversimplified representation of connections between nodes due to the fact that the barriers are classified either as completely insurmountable or completely 


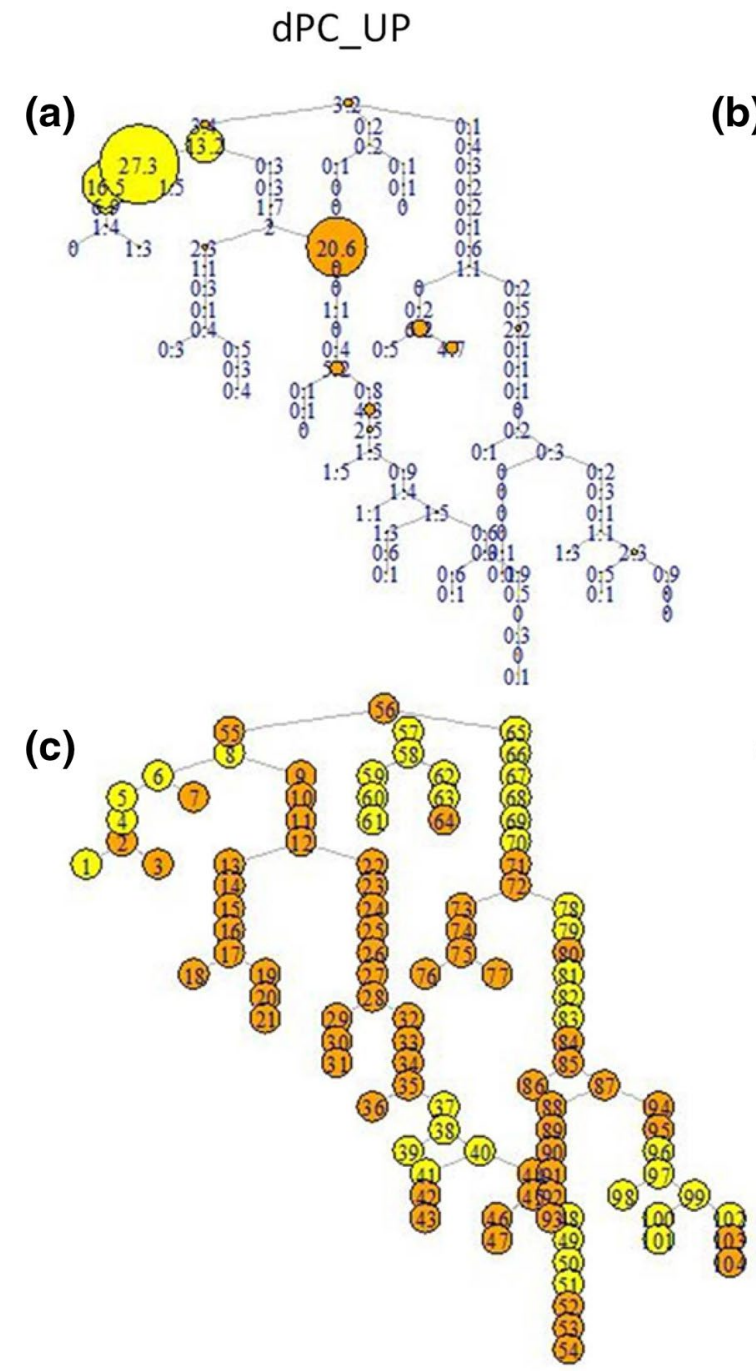

Fig. 6 Graph representation of the differences between the upstream and downstream passability using the $\mathrm{dPC}$ index. Charts (a) and (b) represent a bubble diagram where maximum variations among the

surmountable, in contrast to the probabilistic approach provided by the PC index.

The observed ranking differences between the dIICconnector and dPCconnector are caused by the different connectivity models on which each of them relies (binary against probabilistic connections) (Baranyi et al. 2011). The dIIC ranking values present important differences regarding $\mathrm{dPC}$ values (see Results section) because of the characteristics of each index: the IIC gives more value to the impassability of the barriers, while the PC values give more importance to the position of the dam in the fluvial network, beyond a simplified consideration of whether or not a given obstacle is impassable.

In this case, the PC index is required because some of the obstacles in the case study rivers are not absolutely
dPC_DOWN

(b)

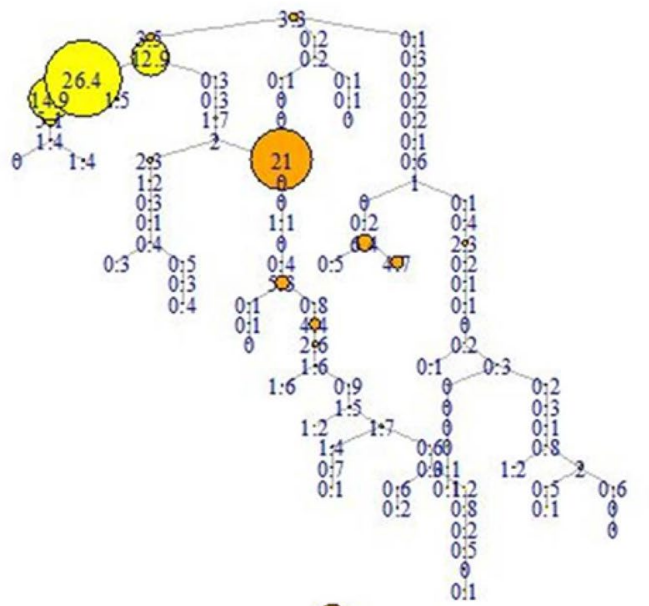

(d)

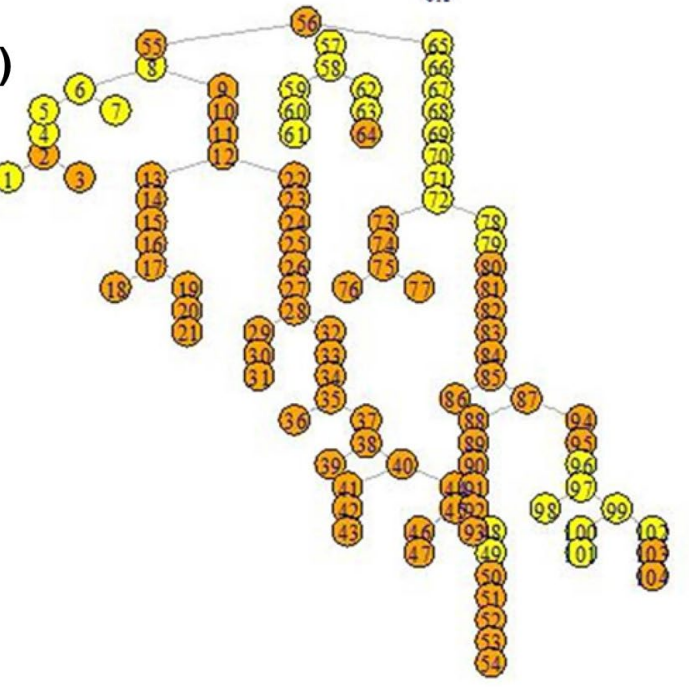

results by using symmetric and asymmetric models are shown. Charts (c) and (d) show the type of bias on the symmetric model assessment: overestimation (yellow) and underestimation (orange)

insurmountable, depending on the physical characteristics of the obstacle and the biology of the chosen fish species. Therefore, it is important that the classification of the obstacles is not reduced to only being insurmountable or surmountable, but that it also possesses intermediate values, depending on the analysed parameters. Another important aspect is that the ability of the fish species to pass barriers must be measured in two ways, upstream and downstream. The CI provides passability values for each obstacle, allowing us to determine the probabilities of crossing every barrier in both directions for the selected species and thus allowing for the generation of a bidirectional graph. Then, only the PC index enables the consideration of this asymmetrical characteristic. 


\section{Asymmetric model versus symmetric model}

Traditionally, when it is established that both directions are equally important in determining the overall connectivity of river networks, downstream passability receives less attention than does the upstream one (González Fernández et al. 2010). The importance of asymmetry of movement in dendritic systems (Padgham and Webb 2010; Grant 2011) is a relevant condition to apply an asymmetric graph resolution to prioritise barriers that suppose an obstacle for species movement. If a single passability value is assigned to quantify the relevance of an obstacle, symmetric passability is assumed. In this work, this assumption is avoided by considering different passability values in those obstacles where movement is easier in one direction than in the other. To assess the importance of neglecting the asymmetric passability of obstacles in these studies, the results of both approaches were compared. After comparing the results from both approaches (Table 2), the ranking of obstacles according to the dPC in both models is congruent for the most important obstacles but not for all of them. In the connector fraction, a higher variability between the models can be observed in the connector ranking.

When analysing passability in the asymmetrical model, it was found that upstream and downstream values were similar in most of the cases (see Fig. 1c). Therefore, it appears that symmetric passabilities can be assumed. However, while the mean difference between the downstream and upstream CI is small, the asymmetric model was found to be helpful for improving the downstream passability in some cases. Both models are really useful, but the asymmetric model is useful to refine the model and evaluate more subtle changes in connectivity. The asymmetric model may be especially useful for analysing clusters of close barriers because of the differences in their passability due to flow conditions. While the asymmetric model may be preferable in networks with small obstacles, the symmetric model may be useful in rivers with large insurmountable dams. Although the barrier ranking was rather similar for both the symmetric and asymmetric models, the prioritisation of conservation measures depends on more parameters, i.e. actuations on small barriers with different levels of passability located in headwaters could be more cost-effective than the elimination of a large dam.

The asymmetrical methodological framework distinguished between some barriers whose downstream passability might be increased by soft actions from other barriers where their upstream passability will only be increased by the implementation of more budget-demanding measures, such as hard fish passage constructions or dam wall demolitions.

\section{Further research}

The assumption of symmetric passabilites may not always be affordable (Baranyi et al. 2011). Previous studies of fluvial connectivity (Erös et al. 2011; Segurado et al. 2013, 2014) have only considered the ranking of river segments to prioritise those that maintain river connectivity, while the study of links (named connectors in this research) has received little attention. Conefor can calculate the link importance by means of the link improvement tool, which creates a rank of barriers that suppose a hindrance to connectivity. This tool allows the decision makers to establish priorities in dam management by providing information on improvement of the connectivity when each obstacle is eliminated relative to the current situation (Bednarek 2001). An extension of this application that includes dam placement in the riverine network, the height and the material with which dams are built may lead to a more realistic model of connectivity in which differential passability plays a crucial role. We consider that further research on this area should be conducted.

Climate change prospects may increase water storage necessities and the pressure to build more dams (Oki and Kanae 2006), increasing habitat fragmentation and threatening important segments that maintain river connectivity (Rahel and Olden 2008). Mediterranean rivers are especially fragile to fragmentation produced by water scarcity. For that reason, we consider it essential to study these types of rivers because they will be particularly affected in the future by climate change predictions (Santiago et al. 2015). In this situation of increasing water scarcity, measures to wisely conciliate human exploitation and river conservation become essential for ensuring the structure and functions of healthy ecosystems.

Acknowledgements Part of this study has been supported by 7 th Framework Programme of the European Union (DURERO Project C1 3913442). We thank Gustavo González and his team for the valuable information about connectivity and barrier passability in the Duero River Basin. We would like to express our thanks to Pablo Moreno and Vanesa Martínez-Fernández for their comments which improved the quality of the paper. Two anonymous reviewers are thanked for their helpful comments and insights.

\section{References}

Baranyi G, Saura S, Podani J, Jordán F (2011) Contribution of habitat patches to network connectivity: redundancy and uniqueness of topological indices. Ecol Indic 11:1301-1310

Bednarek AT (2001) Undamming rivers: a review of the ecological impacts of dam removal. Environ Manage 27(6):803-814

Bjornn TC, Peery CA (1992) A review of literature related to movements of adult salmon and steelhead past dams and through reservoirs in the Lower Snake River. Technical Report 92-1, US 
Fish and Wildlife Service, Idaho Cooperative Fish and Wildlife Research Unit, University of Idaho, Moscow

Bodin Ö (2009) Ecological topology and networks. In: Meyers S. (ed) Encyclopedia of complexity and system Science. Springer, New York, pp 2728-2744

Bodin Ö, Saura S (2010) Ranking individual patches as connectivity providers: integrating network analysis and patch removal experiments. Ecol Modell 221:2393-2405

Bourne CM, Kehler DG, Wiersma YF, Cote D (2011) Barriers to fish passage and barriers to fish passage assessments: the impact of assessment methods and assumptions on barrier identification and quantification of watershed connectivity. Aquat Ecol 45:389-403

Branco P, Segurado P, Santos JM, Pinheiro P, Ferreirs MT (2012) Does longitudinal connectivity loss affect the distribution of freshwater fish? Ecol Eng 48:70-78

Calabrese JM, Fagan WF (2004) A comparison shoppers' guide to connectivity metrics: trading of between data requirement and information content. Front Ecol Environ 2:529-536

Carranza ML, D’Alessandro E, Saura S, Loy A (2012) Connectivity providers for semi-aquatic vertebrates: the case of the endangered otter in Italy. Landscape Ecol 27:281-290

CHD (2009) Plan hidrológico del Duero. Plan hidrológico de la parte española de la demarcación hidrográfica del Duero propuesta de proyecto de plan hidrológico de cuenca. España

Cote D, Kehler DG, Bourne C, Wiersma YF (2009) A new measure of longitudinal connectivity for stream networks. Landscape Ecol 24:101-113

Erös T, Schmera D, Schick RS (2011) Network thinking in riverscape conservation-a graph-based approach. Biol Conserv 144:184-192

Erös T, Olden JD, Schick RS, Schmera D, Fortin M-J (2012) Characterizing connectivity relationships in freshwaters using patchbased graphs. Landscape Ecol 27:303-317

Erôs T, Grant, EHC (2015) Unifying research on the fragmentation of terrestrial and aquatic habitats: patches, connectivity and the matrix in riverscapes. Freshw Biol 60(8):1487-1501

González Fernández G, Pérez Cardenal D, Miguelez Carbajo D, Gallego García R, Fernández Suárez R, Álvarez Durango E, Canal Rubio P, Roa Álvarez I, Rosa Cubo E, Seisdedos Fidalgo P (2010) Diagnóstico de la conectividad longitudinal en la Cuenca del Duero. Ministerio de Medio Ambiente, Medio Rural y Marino. Available on http://www.chduero.es/acciona5/ metodologia/ic.pdf

Gough P, Philipsen P, Schollema PP, Wanningen H (2012) From sea to source: International guidance for the restoration of fish migration highways. Regional Water Authority Hunze en Aa's. The Netherlands

Grant EHC (2011) Structural complexity, movement bias, and metapopulation extinction risk in dendritic ecological networks. J N Am Benthol Soc 30(1):252-258

Grant EHC, Lowe WH, Fagan WF (2007) Living in the branches: population dynamics and ecological processes in dendritic networks. Ecol Lett 10(2):165-175

Hilty JA, Lidicker WZ Jr, Merenlender A (2012). Corridor ecology: the science and practice of linking landscapes for biodiversity conservation. Island Press

Januchowski-Hartley SR, McIntyre PB, Diebel M, Doran PJ, Infante DM, Joseph C, Allan JD (2013) Restoring aquatic ecosystem connectivity requires expanding inventories of both dams and road crossings. Front Ecol Environ 11(4):211-217

Junta de Castilla y León (1997) Estudio de las poblaciones piscícolas del río Cega (Segovia). Technical Report: Estudios Biológicos, Madrid

Kondolf GM, Boulton AJ, O’Daniel S, Poole GC, Rahel FJ, Stanley EH, Whol E, Bång A, Carlstrom J, Cristoni C, Huber H, Koljonen S, Louhi P, Nakamura K (2006) Process-based ecological river restoration: visualizing three-dimensional connectivity and dynamic vectors to recover lost linkages. Ecol Soc 11(2):5

Lucas MC, Baras E, Thom TJ, Duncan A, Slavík O (2001) Migration of freshwater fishes, vol 47. Blackwell Science, Oxford

Minor ES, Urban DL (2007) Graph theory as a proxy for spatially explicit population models in conservation planning. Ecol Appl 17:1771-1782

Minor ES, Urban DL (2008) A graph-theory framework for evaluating landscape connectivity and conservation planning. Conserv Biol 22:297-307

Nicola GG, Elvira B, Almodovar A (1996) Dams and fish passage facilities in the large rivers of Spain: effects on migratory species. Large Rivers 10:375-379

O'Hanley JR (2011) Open rivers: barrier removal planning and the restoration of free-flowing rivers. J Environ Manage 92(12):3112-3120

O'Hanley JR, Tomberlin D (2005) Optimizing the removal of small fish passage barriers. Environ Model Assess 10(2):85-98

Oki T, Kanae S (2006) Global hydrological cycles and world water resources. Science 313(5790):1068-1072

Padgham M, Webb JA (2010) Multiple structural modifications to dendritic ecological networks produce simple responses. Ecol Modell 221(21):2537-2545

Pascual-Hortal L, Saura S (2006) Comparison and development of new graph-based landscape connectivity indices: towards the priorization of habitat patches and corridors for conservation. Landscape Ecol 21:959-967

Rahel FJ, Olden JD (2008) Assessing the effects of climate change on aquatic invasive species. Conserv Biol 22:521-533

Rivers-Moore N, Mantel S, Ramulifo P, Dallas H (2016) A disconnectivity index for improving choices in managing protected areas for rivers. Aquatic Conservation: Marine Freshwater Ecosystems 26(S1):29-38

Santiago JM, García de Jalón D, Alonso C, Solana J, Ribalaygua J, Pórtoles J, Monjo R (2015) Brown trout thermal niche and climate change: expected changes in the distribution of cold-water fish in central Spain. Ecohydrol

Saura S, Pascual-Hortal L (2007) A new habitat availability index to integrate connectivity in landscape conservation planning: comparison with existing indices and application to a case study. Landscape Urban Plan 83:91-103

Saura S, Rubio L (2010) A common currency for the different ways in which patches and links can contribute to habitat availability and connectivity in the landscape. Ecography 33:523-537

Saura S, Torné J (2009) Conefor Sensinode 2.2: a software package for quantifying the importance of habitat patches for landscape connectivity. Environmental Modelling \& Software 24: 135-139.

Saura S, Torné J (2012) Conefor 2.6 user manual (April 2012). Universidad Politécnica de Madrid. Available at http://www.conefor.org.

Schick RS, Lindley ST (2007) Directed connectivity among fish populations in a riverine network. J Appl Ecol 44:1116-1126

Segurado P, Branco P, Ferreira MT (2013) Prioritizing restoration of structural connectivity in rivers: a graph based approach. Landscape Ecol 28:1231-1238

Segurado P, Branco P, Avelar AP, Ferreira MT (2014) Historical changes in the functional connectivity of river based on spatial networks analysis and the past occurrences of diadromous species in Portugal. Aquatic Sci

Tockner K, Schiemer F, Ward JV (1998) Conservation by restoration: the management concept for a river-floodplain system on the Danube River in Austria. Aquat Conserv 8:71-86

Ward JV (1989) The four-dimensional nature of the lotic ecosystem. J N Am Benthol Soc 8:2-8

Wiens JA (2002) Riverine landscapes: taking landscape ecology into the water. Freshw Biol 47(4):501-515 